Revista Signos

2008, 41(67)

$115-117$

\section{Discurso de recepción a la Doctora Juana Marinkovich Ravena como Miembro Correspondiente por Valparaíso de la Academia Chilena de la Lengua}

Valparaíso, 20 de octubre, 2006

\author{
Andrés Gallardo \\ Miembro de Número, Academia Chilena de la Lengua \\ Universidad de Concepción \\ Chile
}

La Academia Chilena de la Lengua me ha encomendado la muy grata misión de recibir formalmente a Juana Marinkovich como Miembro Correspondiente en Valparaíso de la Corporación.

Juana Marinkovich Ravena nació en Punta Arenas, pero su actividad académica está ligada principalmente a su alma mater, la Pontificia Universidad Católica de Valparaíso, donde obtuvo su título de Profesora de Francés y donde se ha desempeñado como docente e investigadora desde los comienzos de su vida laboral. Realizó sus estudios de posgrado en Santiago, en la Pontificia Universidad Católica de Chile, en la cual obtuvo el grado de Magíster en Letras con Mención en Lingüística. Culminó su formación con un doctorado en Filología Románica, también con mención en Lingüística, en la Universidad de Chile. En la Universidad de Montreal, Canadá, se especializó en los problemas de la traducción y obtuvo el grado de Maître es Arts.

Como docente, se ha desempeñado en todos los niveles de la enseñanza superior, dictando cursos de lingüística general, de semántica y lexicografía, de terminología, de psicolingüística, de enseñanza de lenguas y traducción, pero sin duda sus intereses, tanto en la investigación como en su práctica docente, la llevan hacia el campo de la lingüística del texto, el análisis crítico del discurso y, muy especialmente, el campo interdisciplinario en pleno desarrollo del estudio de la producción de textos escritos. En esta última línea ha llevado adelante importantes proyectos de investigación, como "Un programa interdisciplinario de enseñanza de la escritura" (1997-1998), patrocinado por su Universidad, "Hacia un perfil de la competencia de escolares chilenos en producción del discurso escrito en dos tipologías textuales" (1999-2001) y "La competencia argumentativa oral en el aula: Un estudio exploratorio con estudiantes de Enseñanza Media" (2006-2009), ambos al amparo de FONDECYT, y 
"LECTES, Programa de Optimización de la competencia estratégica para comprender y producir textos escritos" (2002-2005), con el patrocinio de FONDEF.

Sus publicaciones se enmarcan en esta misma línea, y llevan la marca de una orientación práctica, asentada, eso sí, en sólidos fundamentos teóricos. Entre estas publicaciones destacan libros como "Un programa interdisciplinario de enseñanza de la escritura" (1999), "La escritura como proceso: Fundamentos y práctica en el aula" (en prensa), y "LECTES: Programa de Lectura y Escritura" (2006), en conjunto con Marianne Peronard y Giovanni Parodi. Similares características tienen sus numerosos artículos publicados en diversas revistas nacionales y extranjeras, entre los cuales cabe mencionar: "Hacia una representación de la escritura en el aula" (Revista Signos, 1996), "Una experiencia innovativa. El periódico como estrategia de aprendizaje" (Revista Pensamiento Educativo, 1997), "Cognitive-cooperative strategies in the writing classroom", en el volumen colectivo Psycholinguistics in the threshold of the year 2000 (1999), "El análisis del discurso y la intertextualidad" (Boletín de Filología de la Universidad de Chile, 1998-1999), "Un estudio exploratorio acerca de los tipos de textos escritos que se producen en el aula" (en el libro colectivo Texto y Discurso, publicado en homenaje a Luis Gómez Macker, 1999), "Una propuesta de evaluación de la competencia textual narrativa" (Revista Signos, 1999), "Aproximaciones al análisis intertextual del discurso científico" (Revista Signos, 2001), "Enfoques de proceso en la evaluación de textos escritos" (Revista Signos, 2002), "Foco narrativo y foco informativo: Dos dimensiones para la descripción de los manuales en la formación técnico-profesional" (Revista Signos, 2004, en colaboración con Yanina Cademártori), "Las estrategias de reformulación: El paso desde un texto fuente a un texto de divulgación didáctica" (Revista de Literatura y Lingüística, 2005) y "La nominalización como un recurso de cohesión léxica en los manuales de la formación técnico-profesional” (RLA Revista de Lingüística Teórica y Aplicada, 2005).

Me he extendido algo en la lista, por cierto muy incompleta, de las publicaciones de Juana Marinkovich porque los meros títulos ya ponen de manifiesto un rasgo que ya he mencionado, cual es su decidida vocación hacia la detección y solución de problemas reales relacionados con el uso de la lengua, predominantemente escrita, en la práctica concreta de nuestros estudiantes, tanto de enseñanza media como de enseñanza superior. Esta actitud revela un hecho de relevancia cultural no menor, cual es una saludable madurez de nuestros lingüistas. Durante mucho tiempo los lingüistas, y los chilenos nos sumamos entusiastamente a la tendencia internacional, fuimos formados en la convicción de que nuestro negocio eran los problemas teóricos relacionados con "el" lenguaje humano y, muy especialmente, fuimos instruidos en el credo fundamentalista de que, en lo que se refiere a la lengua materna, no tenemos derecho a intervenir en el comportamiento de los demás. Señalarles a nuestros conciudadanos, y sobre todo a nuestros estudiantes, caminos para mejorar su competencia idiomática recibía el mote descalificador de "purista" y nadie que se preciara de científico se atrevía a asumir tan nefasta condición. El resultado fue deplorable, pues los profesores de lengua materna no orientaban ni enseñaban gramática, y los profesores 
de lenguas extranjeras se dedicaban a entregar estructuras idiomáticas "casi" vacuas a sangre fría. Felizmente, como he dicho, las personas y las disciplinas maduran, y personas como Juana Marinkovich han desarrollado en poco tiempo una labor gigantesca, que trata de paliar el vacío en que ciertas posiciones teórica llegadas de fuera, y encima mal asimiladas, nos sumieron.

No en vano Chile fue el nido que acogió la genialidad de Andrés Bello, cuyas enseñanzas revivimos hoy con entusiasmo. No se trata, desde luego, de reeditar sin más la vieja gramática normativa, que bien entendida tan mala no es, ni de copiar modelos extranjeros, que mucho bien pueden hacernos. Se trata de que, desde nuestra tradición académica y desde nuestra realidad hispanoamericana, nos incorporemos a las zonas de desarrollo científico y humanístico que demuestren ser más sólidas y más productivas, y de que sobre esa base elaboremos un pensamiento propio y líneas de trabajo que se enraícen y hallen sentido en nuestro medio. Este es el esfuerzo que Juana Marinkovich, y una promisoria generación de lingüistas formados en nuestras universidades, están haciendo. Un resultado muy concreto habrá de ser la renovación, en un sentido de sensibilidad cultural y de solidez teórica y técnica, de los textos de estudio que utilizan los estudiantes chilenos de educación básica, media y superior, textos que muchas veces contribuyen más a desincentivar el conocimiento que a acrecentarlo.

Esta actitud renovada, que aúna la dimensión teórica y los intereses prácticos, no ha sido ajena a la Academia Chilena de la Lengua, que con renovados bríos ha asumido su condición de entidad de estudio de la lengua y de servicio a sus hablantes. Por eso, la Academia se ha fijado en los antecedentes de la profesora Marinkovich, en su formación, en su productividad y, muy especialmente, en su disposición a trabajar en equipo. Desde el día mismo en que fue invitada a la Corporación, Juana Marinkovich se integró a la comisión de Lexicografía, donde su aporte se ha hecho notar en el tratamiento de los problemas lexicográficos más intrincados, y en la minucia diaria de la recolección de materiales para el proyecto que en lo inmediato nos concita, cual es el Diccionario de Uso del Español de Chile, trabajo que deberá estar terminado el año 2010, como un saludo de la Academia Chilena de la Lengua al bicentenario de la Nación. Con la solvencia técnica y con la calidad humana de una profesional como Juana Marinkovich este proyecto se está haciendo claramente factible. Son ellas razones todas para darle a esta colega y amiga la más cordial y esperanzada bienvenida a la Academia Chilena de la Lengua. 